\title{
Application of a novel enzymatic sterilisation Time Temperature Integrator
}

\author{
G.S. Tucker ${ }^{2}$, P.W. Cox ${ }^{1}$, H. M. Brown ${ }^{2}$, S. Bakalis ${ }^{1}$, P.J. Fryer ${ }^{1}$, M.W. Adams ${ }^{3}$ \\ 1. Centre for Formulation Engineering, University of Birmingham, B15 2TT \\ UK. Email: P.J.Fryer@bham.ac.uk \\ 2. Campden and Chorleywood Food Research Association, Chipping Campden, \\ UK.
}

3. Department of Biochemistry \& Molecular Biology, University of Georgia, USA.

\begin{abstract}
A highly stable amylase has been identified from a hyper-thermophilic archaeon Pyrocoocus furiosus, which is suitable for the construction of Time Temperature Integrators (TTIs) for use in the food industry. Previously, amylases from terrestrial Bacilli have provided the feed stock for enzymatic TTIs. However, their application has been limited to pasteurisation; the new amylase now makes possible the application of such technology to sterilisation processes. The amylase demonstrates excellent thermal properties for its application as a "safety" TTI; namely an isothermal decimal reduction time at $121.1^{\circ} \mathrm{C}$ of $22.5 \pm 4$ minutes $(21.5 \pm 2$ under non isothermal $)$ and a $\mathrm{z}$-value of 10 $\pm 1.5^{\circ} \mathrm{C}$.
\end{abstract}

The enzymatic TTI have a distinct number of advantages over other temperature measurement technologies, e.g. thermocouples or data loggers, for the examination of continuous processes. Their small and near neutrally buoyant construction, $2.5 \mathrm{~mm} x$ $8.0 \mathrm{~mm}$ with $25 \mu \mathrm{l}$ of enzyme solution, makes them ideal for introduction into fluids or within food particulates. They are robust enough to pass through nearly all processing equipment; the encapsulation is from silicon tubing with elastomer plugs which also has thermal properties close to that of water. Post processing analysis is quick, inexpensive and accurate also the enzyme, an amylase is generally regarded as safe.

The sterilisation TTIs have been tested in reel \& spiral and Largarde steam air retorts in cans and doypacks and showed $\mathrm{F}_{0}$-values appropriate to the $\log$ reductions of Clostridium botulinum spores.

\section{Introduction}

Thermal processing is probably the most important method for preserving food, and sterilisation processes such as canning are still immense business. The most important heat-resistant pathogen that might survive the thermal processing of low-acid foods is the spore-forming organism Clostridium botulinum; a sterilisation process must reduce the probability of a single Clostridium botulinum spore surviving in a low-acid product to one in $10^{12}$ the so called 'botulinum cook'. This is the standard process and is achieved by an equivalent process of 3 minutes at $121.1^{\circ} \mathrm{C}$, referred to as Fo 3 (FDA, 2005).

Additionally, manufacturers must prove that their products and processes are 
safe. Validation is usually carried out with thermocouple or loggers, but this can be difficult for products with freely moving particulates or for some packaging types. If temperature probes cannot be used, alternative approaches to validating microbiological process safety are required, such as:

- Microbiological methods, where non-pathogenic analogue organisms, with similar temperature-induced death kinetics to the target pathogen are used (Brown, et al., 1984). The enumeration of the post process surviving organisms allows for the calculation of the log reduction and sterilisation value.

- Simulated trials carried out in a laboratory where the heat transfer conditions of the process are replicated process value estimates are then made via models such as Ball (1923), NumeriCAL (FMC Inc., USA) or CTemp (Tucker, et al., 1996) predict the required process conditions to achieve a desired sterilisation value.

- Mathematical process models that predict, for example, the temperature-time history of the critical food during a process (Sastry, 1986; McKenna and Tucker, 1991).

Another method that has extensively been applied to pasteurisation processes are time-temperature integrators (TTIs). A TTI can be defined as a small measuring device that shows a time-temperature dependent irreversible change that mimics the change of a target attribute when exposed to the same conditions. In practice, a TTI can be an enzyme, such as amylase or peroxidase, that denatures as it is heated in a buffer. If the reaction kinetics of the temperature-induced denaturation match those of the first order microbial death kinetics, the enzyme can be used as a biochemical marker of a process. The development of TTIs has received considerable attention recently (see reviews by Maesmans et al., 1994; Hendrickx et al.,1995). It is now possible to use an amylase-based TTI for most commercial pasteurisation processes, from $70^{\circ} \mathrm{C}$ up to $95^{\circ} \mathrm{C}$. Usually, TTIs use amylases from bacterial sources such as Bacillus amyloliquefaciens or licheniformis and the feasibility of extending its useable range upwards into sterilisation temperatures was demonstrated by drying amylases to precise moisture levels (Van Loey, et al., 1997, Guiavarc'h, 2003). Laboratory results were encouraging and showed that different levels of moisture content gave a range of heat stabilities. However, practical issues made industrial application difficult (Tucker and Wolf, 2003). Therefore, a different method is required for a sterilisation TTI.

Also Tucker et al. (2005) specifically, the measured z-values for different amylases and found them to be in the range 9 to $10^{\circ} \mathrm{C}$, ideal for bacterial spore destruction. Hence, an amylase was considered to provide the greatest chance of finding a TTI for use in sterilisation processes. The key was to locate an organism that has evolved in high temperature conditions and that produces amylase as it metabolises. Microorganisms from hostile environments such as volcanic vents seemed attractive (Stetter, 1996). These 'hyperthermophilic' organisms represent a relatively unexplored research area for food applications but one with enormous potential for supply of heat stable enzymes; as a number of bacteria capable of growing at or above $100^{\circ} \mathrm{C}$ have been isolated (Vieille and Zeikus, 2001). It was hypothesised that amylases from hyperthermophilic organisms might be inherently heat stable to hydrolyse starches in the natural environmental (Vieille and Zeikus, 2001).

The candidate organism: Pyrococcus furiosus was of great interest for the development of a sterilisation TTI because of the reported heat stability of its amylases (Koch, et al., 1990). The archaeon was isolated by Fiala and Stetter (1986) from shallow 
thermal waters near Vulcano Island, Italy. P. furiosus is an obligate anaerobic, hyperthermophilic archaeon and according to its genomic sequence, $P$. furiosus contains at least five enzymes that would be predicted to have amylase-type activity and a recombinant form of an extracellular amylase has been characterized (Jorgensen, Vorgias and Antranikian, 1997). P. furiosus is therefore a potentially rich source of amylolytic-type enzymes, although their exact function and the precise pathway by which starch is metabolised is not clear. It should be remembered that a strong tenet through out this work was to express these amylases from the native organism and not to genetically modify it or express the amylase via a third party vector.

$P$. furiosus amylase activity has been measured over broad temperature (40 $140^{\circ} \mathrm{C}$ ) with an optimum activity at close to $100^{\circ} \mathrm{C}$ No loss of activity was detected after 6 hours of incubation at $90^{\circ} \mathrm{C}$ and at $120^{\circ} \mathrm{C}$ and about $10 \%$ of the initial activity was measured after 6 hours (Koch et al., 1990),. This equated to a decimal reduction time at $120^{\circ} \mathrm{C}$ of 6 hours $\left(D_{120}=6 \mathrm{~h}\right)$. To inactivate the enzyme completely, incubation had to be performed at $130^{\circ} \mathrm{C}$ for at least $1 \mathrm{~h}$. Thus this material looks suitable for a sterilisation TTI.

But for successful use, the kinetics of the thermal destruction of amylase need to show sufficient heat stability for some of the active amylase structure to remain after several minutes heating at $121.1^{\circ} \mathrm{C}$, characterized by the $\mathrm{D}$-value i.e. partially survive an $\mathrm{F}_{0} 3$ cook. However, the amylase must also display a $\mathrm{z}$-value close to $10^{\circ} \mathrm{C}$, and so represent Clostridium botulinum spores.

\section{Materials and Methods}

Work was undertaken at the University of Georgia, USA to grow Pyrococcus furiosus on a rich medium containing yeast extract with peptides as the primary carbon sources (Adams et al., 2001; Schut et al., 2003). Total supernatant protein was extracted via an ammonium sulphate cut. This was dialysed and freeze dried to produce a freeze-dried powder (FDP) which could be rehydrated for preparation of TTIs. TTI tubes, were made in a similar fashion to those used for pasteurisation TTIs (Tucker et al., 2003).

A starch-iodine assay was used to assess amylase activity by incubating at $92^{\circ} \mathrm{C}$ a mixture of soluble starch, acetate buffer (see Tucker et al, 2006 for details). This assay was chosen for the Pyrococcus furiosus amylase because of the need to incubate at temperatures above $90^{\circ} \mathrm{C}$ for the analyses.

From a series of isothermal experiments D-values were derived. However, the log-linear relationship between these D-values and temperature to allow for the z-value to be determined could not be initially performed due to insufficient FDP. Initial isothermal trials centred on measuring the $\mathrm{D}$-value at $121^{\circ} \mathrm{C}$ to confirm the amylase heat stability. Non-isothermal methods of obtaining D- and importantly zvalue data were used (De Cordt et al., 1992). Sterilisation TTIs were attached to temperature probes and the temperature-time profile, $\mathrm{T}(\mathrm{t})$ recorded. After the TTI had been through the process it was assayed. Amylase activities from the TTIs and the temperatures from the probes were converted sterilisation values using the familiar Ball equation and its analogous form for TTIs (Equation 1): 


$$
\mathrm{F}=\int_{0}^{\mathrm{t}} 10^{\frac{\mathrm{T}(\mathrm{t}) \text { Tref }}{\mathrm{z}}} \cdot \mathrm{dt}=D_{t}\left(\frac{A_{1}}{A_{2}}\right)
$$

where A1 is the initial amylase activity and A2 the remaining activity after processing

Two variables define the F-values calculated with the sterilisation TTI and with temperature sensors: $\mathrm{D}_{\mathrm{T}}$-value for reduction in amylase activity as measured with the sterilisation TTI and the z-value as calculated from measured times and temperatures. A number of matching pairs of TTIs and integrated temperature values gave pairs of calculated F-values. To obtain estimated values for $\mathrm{D}_{\mathrm{T}}$ and $\mathrm{z}$ the sum of the minimum absolute difference between matching paired values was selected. Two sets of experimental trials were carried out to challenge the measurement range of the TTI and thus estimate $\mathrm{D}_{\mathrm{T}}$ and $\mathrm{z}$. The data sets used different product heating rates as well as different process temperatures between 121 and $131^{\circ} \mathrm{C}$.

Trial 1: The first processing style used a commercial Lagarde steam-air retort. Products were packaged in plastic pouches and glass jars. Various different thermal processes were given to achieve commercial values for sterilisation. Different heating rates from the products allowed the time-temperature data to change the lethal rate accumulation. $\mathrm{D}_{\mathrm{T}}$ and $\mathrm{z}$ from trial 1 were used to estimate $\mathrm{F}$-values for trial 2.

Trial 2: The second processing style was a bar simulator for an FMC reel and spiral cooker-cooler with cylindrical metal cans. In this system, fast axial rotation (FAR) occurred during parts of the process. This resulted in extremely efficient heat transfer. Water (0), 1 and $2 \% \mathrm{w} / \mathrm{w}$ starch solutions were used to produce different heating rates in the product. Two different process temperatures were used to provide data to challenge the kinetic calculations at 124 and $131^{\circ} \mathrm{C}$.

For each system one sterilisation TTI was attached to the tip of a Tracksense (Ellab UK Ltd, Kings Lynn) temperature sensor at a common measuring position.

\section{Results}

\section{Measurement of $D_{T}$ by isothermal methods}

Due to the limited amounts of enzyme available a high concentration of FDP was used $(25 \mathrm{mg} / \mathrm{ml})$, and the TTI solution diluted $(5 \mathrm{mg} / \mathrm{ml})$ before the assay as compared to the commonly used pasteurisation TTIs. This allowed four replicates to be produced from the one sample and so four points were obtained for calculating the gradient. Figure 1 shows the plot of logarithm of activity ratio (initial activity / final activity) as a function of heating time. The $\mathrm{D}_{121}$-value was calculated from the regression line as 22.5 minutes.

\section{Measurement of $D_{T}$ and $z$ by non-isothermal methods}

The advantage of non-isothermal TTI calibration is that it is representative of the behaviour of foods during thermal processing. Kinetic data (i.e. D and z) were evaluated with a series of coupled equations. The parameters used to determine values for $\mathrm{D}_{121.1}$ and $\mathrm{z}$ were the differences between $\mathrm{F}$-values calculated from the $\mathrm{t}-\mathrm{T}$ data (referred to as $\mathrm{F}(\mathrm{t}-\mathrm{T})$ ) and from the TTI data (referred to as $\mathrm{F}(\mathrm{TTI})$ ). Equation (1) shows that calculations for $\mathrm{F}(\mathrm{t}-\mathrm{T})$ require the $\mathrm{z}$-value as the input kinetic parameter, whereas those for $\mathrm{F}(\mathrm{TTI})$ requires the D-value. Hence it was possible to 
estimate optimal values for the $\mathrm{D}_{121.1}$ and $\mathrm{z}$.

Figure 2 show the data for the trials. The best fit-line between paired values of $\mathrm{F}(\mathrm{t}-\mathrm{T})$ and $\mathrm{F}(\mathrm{TTI})$ was adjusted to go through the origin; this had a minimal effect on $\mathrm{D}_{121.1}$ and $\mathrm{z}$. It was likely that the minimum measurement for this sterilisation TTI did not extend much below an F-value of 3 minutes, so the lower region of the graph might be subject to a higher error. Data from trial 2 were evaluated using the same $\mathrm{D}_{121.1}=21.45$ minutes and $\mathrm{z}=9.95 \mathrm{C}^{\circ}$ to check on consistency. It can be seen from Figure 2(b) that there was good agreement between $\mathrm{F}(\mathrm{t}-\mathrm{T})$ and $\mathrm{F}(\mathrm{TTI})$, although the highest F-values were $30-40 \%$ different. This level of accuracy was outside of that suggested by Pflug (1987) in which he justified a $20 \%$ difference. Improvement in the accuracy will be achieved when more amylase becomes available for testing and the kinetic experiments can be conducted with replication. However, the accuracy reported here was acceptable for a novel TTI system and demonstrates the potential for amylase from Pyrococcus furiosus as a sterilisation TTIs.

\section{Discussion}

The data illustrated that an amylase from Pyrococcus furiosus displayed a thermal behaviour that was suitable for use as a sterilisation TTI. D-values at $121^{\circ} \mathrm{C}$ were measured as 22.5 minutes for isothermal calibration and 24.5 minutes for nonisothermal calibration. Non-isothermal calibration for the $\mathrm{z}$-value gave $10 \mathrm{C}^{\circ}$, which was the same as the Clostridium botulinurn value of $10 \mathrm{C}^{\circ}$. Fo-values measured with the sterilisation TTI were accurate to within $1.5 \mathrm{~F}_{0}$-value units of the F-values from thermocouples over most of the measurement range. The exception was for the single $\mathrm{F}_{0}$-value of 28 minutes where the TTI system gave a lower value. Obtaining high accuracy at high Fo-values is not as important for process safety where the operating region is in the lower range towards Fo 3. It may be that the sterilisation TTI cannot be used to measure more than one log reduction in amylase activity at the $25 \mathrm{mg} / \mathrm{ml}$ FDP concentration. Operating ranges and further definition of accuracies need to be determined when more FDP is available.

The calibration of any measurement system is an essential requirement in order to provide confidence that the values are correct and within a defined error band (Mehauden et al., 2006). Estimated errors displayed in Figures 2 were $\pm 10 \%$ on time-temperature F-values and $\pm 12.5 \%$ on TTI F-values. These errors were calculated from estimations of inaccuracy with the measurement systems and variability with the relative experiments. Thermocouple temperature measurements were assumed accurate to within $\pm 0.5^{\circ} \mathrm{C}$ under non-isothermal conditions, which converted to about $\pm 10 \%$ at $121.1^{\circ} \mathrm{C}$. Estimated accuracies with TTI F-values were based on a change in D-value of \pm 3 minutes from the 24.5 minutes calculated from the non-isothermal tests. This represented the upper and lower Dvalue limits from the non-isothermal calculations that gave acceptable agreement between F-values from paired TTIs and probes. Further work will be needed to confirm whether this is a realistic assessment and appropriate refinements made.

F-values predicted using the calculated $\mathrm{D}_{1211}$-value for the sterilisation TTIs were consistently within $1.5 \mathrm{~F}$-value units of those from the time-temperature data for F-values in the range 3.0 to 11.0 minutes. With most in-pack thermal processes operating at around Fo-values of 6 to 12 minutes, this is an acceptable measurement range and level of accuracy. Continuous thermal processes with particulates usually operate to substantially higher Fo-values because of the uncertainty involved with their measurement. Thus, an error of \pm 1.5 minutes on a measured $F$-value in the region of 
20-30 minutes would not be an issue.

\section{Conclusions}

A candidate sterilisation TTI has been identified and tested based on protein extracts containing Pyrococcus furiosus amylase. The measurement range for this sterilisation TTI allowed two objectives to be realised; namely measuring process values at $121^{\circ} \mathrm{C}$ and to allow for process optimisation.

Limitations in the quantity of FDP did not make it possible to complete all the testing. Further experimental work is planned to address the following:

- The best storage conditions need to be determined for the FDP and of the prepared sterilisation TTI tubes.

- What level of amylase purification is required? This is because a reduction in activity was found when the sterilisation TTIs were stored chilled, and it thought to be throught the action of proteases in the FDP.

- What intrinsic variability should be expected for the sterilisation TTI? As TTIs will have many applications in industrial thermal processes it will be necessary to understand the absolute accuracy of F-values estimated from the TTIs (see Mehauden et al., 2006).

- How to guarantee long term supply of the FDP with reproducible heat stability properties. $P$. furiosus fermentation may not be the best method to produce heat stable amylase. There are reports of the gene being expressed in bacteria such as E. coli or in moulds. Reports suggest that the amylase from an E. coli retains its heat stability but it has not been tested in the same way as for a sterilisation TTI. But this approach may not be applicable for all companies due to concerns relating to GMO's and genetic engineering.

\section{Acknowledgements}

Funding from DEFRA LINK grant AFM 194 and the supporting industrial companies is gratefully acknowledged. Special thanks go to Johnston Pickles (Baxters of Speyside Ltd) and Steve Tearle (Masterfoods) for generating temperature data for the non-isothermal calibration. Research conducted in the Adams laboratory was supported in part by grants (BES-0317911 and MCB 0129841) from the US National Science Foundation

\section{References}

Adams, M.W.W., Holden, J.F., Menon,N.L., Schut, G.J., Grunden,N.M., Hou, C., Hutchins, A.M., Jenney, F.E. Jr., Kim, C., Ma, K., Pan, a, Roy, R., Sapra, R., Story, S.V. and Verhagen, M.F.J.M. (2001). Key role for sulfur in peptide metabolism and in regulation of three hydrogenases in the hyperthermophilic archaeon Pyrococcus fitriosus. Journal of Bacteriology, 183, 716-724.

Ball, C.O (1923). Thermal processes for canned foods. Natl. Res. Council Can. Bull. Pt1 No. 37.

Brown, K.L., Ayres, C. A., Gaze, J.E. and Newman, M.E. (1984). Thermal 
destruction of bacterial spores immobilised in food/alginate particles. Food Microbiology, 1, 187-198

De Cordt, S., Hendrickx, M., Maesmans, G., and Tobback, P. (1992). Immobilised a-amylase from Bacillus licheniformis: a potential enzymic time-temperature integrator for thermal processing. International Journal of Food Science and Technology, 27, 661-673.

FDA (2005). Food and Drugs. Chapter 1 - Food and Drug Administration. Department of Health and Human Services. Subchapter B - Food for Human Consumption. Code of Federal Regulations, Title 21, Volume 2. Revised as of April 1, 2005 (21CFR113.3).

Fiala, G. and Stetter, K.O. (1986). Pyrococcus furiosus sp. Nov. represents a novel genus of marine heterotrophic archaebacteria growing optimally at $100^{\circ} \mathrm{C}$. Archives of Microbiology, 145, 56-61.

Guiavarc'h, Y. (2003). Development and use of enzymic time-temperature integrators for the assessment of thermal processes in terms of food safety. PhD Thesis No.570, Katholike Universiteit Leuven, Belgium.

Hendrickx, M., Maesmans, G., De Cordt, S., Noronha, J., Van Loey, A. and Tobback, P. (1995). Evaluation of the integrated time-temperature effect in thermal processing of foods. Critical Reviews in Food Science and Nutrition, 35 (3), 231-262.

Koch, R., Zablowski, A., Spreinat, A. and Antranikian, G. (1990). Extremely thermostable amylolytic enzyme from the archaebacterium Pyrococcus furiosus. FEMS Microbiology Letters. 71, 21-26.

Jorgensen, S., Vorgias, C.E. and Antranikian, G. (1997). Cloning, sequencing, characterization, and expression of an extracellular alphaamylase from the hyperthermophilic archaeon Pyrococcus furiosus in Escherichia coli and Bacillus subtilis. Journal of Biological Chemistry, 272, 16335-16342.

Maesmans, a, Hendrickx, M., De Cordt, S., Van Loey, A., Noronha, J. and Tobback, P. (1994). Evaluation of process value distribution with time temperature integrators. Food Research International, 27, 413-423.

McKenna, A.B. and Tucker, G.S. (1991). Computer modelling for the control of particulate sterilization under dynamic flow conditions. Food Control, 2, 224233.

Mehauden K., Cox P.W., Bakalis S., Simmons M.J.H and Fryer P.J. (2006) Evaluation and verification of the reliability of Time Temperature Integrators made from $\alpha$-amylase of Bacillus amyloliquefaciens IFSET in press.

Pflug, I. (1987). Factors important in determining the heat process value, FT, for low-acid canned foods. Journal of Food Protection, 50, 528-533.

Sastry, S.K. (1986). Mathematical evaluation of process schedules for aseptic processing of low acid foods containing discrete particulates. Journal of Food Science, 51, 1323-.

Schut, G.J., Brehm, S.D., Datta, S. and Adams, M.W.W. (2003). Whole-genome DNA microarray analysis of a hyperthermophile and an archaeon: 
Pyrococcus furiosus grown on carbohydrates or peptides. Journal of Bacteriology, 185, 3935-3947.

Stetter, K.O. (1996). Hyperthermophiles in the history of life. Ciba Foundation Symposium, 202: 1-10, discussion 11-18.

Tucker, G.S., Noronha, J.F. and Heydon, C.J. (1996). Experimental validation of mathematical procedures for the evaluation of thermal processes and process deviations during the sterilization of canned foods. Transactions of the IChemE, Food and Bioproducts Processing, 74, Part C, 140-148.

Tucker, G.S. and Wolf, D. (2003). Time-temperature integrators for food process analysis, modelling and control. R\&D Report No.177, CCFRA, Chipping Campden, Glos., GL55 6LD.

Tucker, G., Cronje, M. and Lloyd, E. (2005). Evaluation of a time-temperature integrator for mild pasteurisation processes. R\&D Report No.215, CCFRA, Chipping Campden, Glos., GL55 6LD.

Tucker , G.S., Brown H.M., Fryer P.J., Cox P.W., Poole F. L., Lee H.-S., Adams, M.W.W. (2006) A Sterilisation Time-Temperature Integrator based on Amylase from the Hyperthermophilic Organism Pyrococcus furiosus. IFSET in press

Van Loey,„N.M., Haentjens, T.H., Hendrickx, M. E. and Tobback, P. P. (1997b). The development of an enzymic time temperature integrator to assess the thermal efficacy of sterilization of low-acid canned foods. Food Biotechnology, 11 (2), 147-168.

Vieille, C and Zeikus, G. (2001). Hyperthermophilic enzymes: Sources, uses and molecular mechanisms for thermostability. Microbiology and Molecular Biology Reviews, 65 (1), 1-43. 


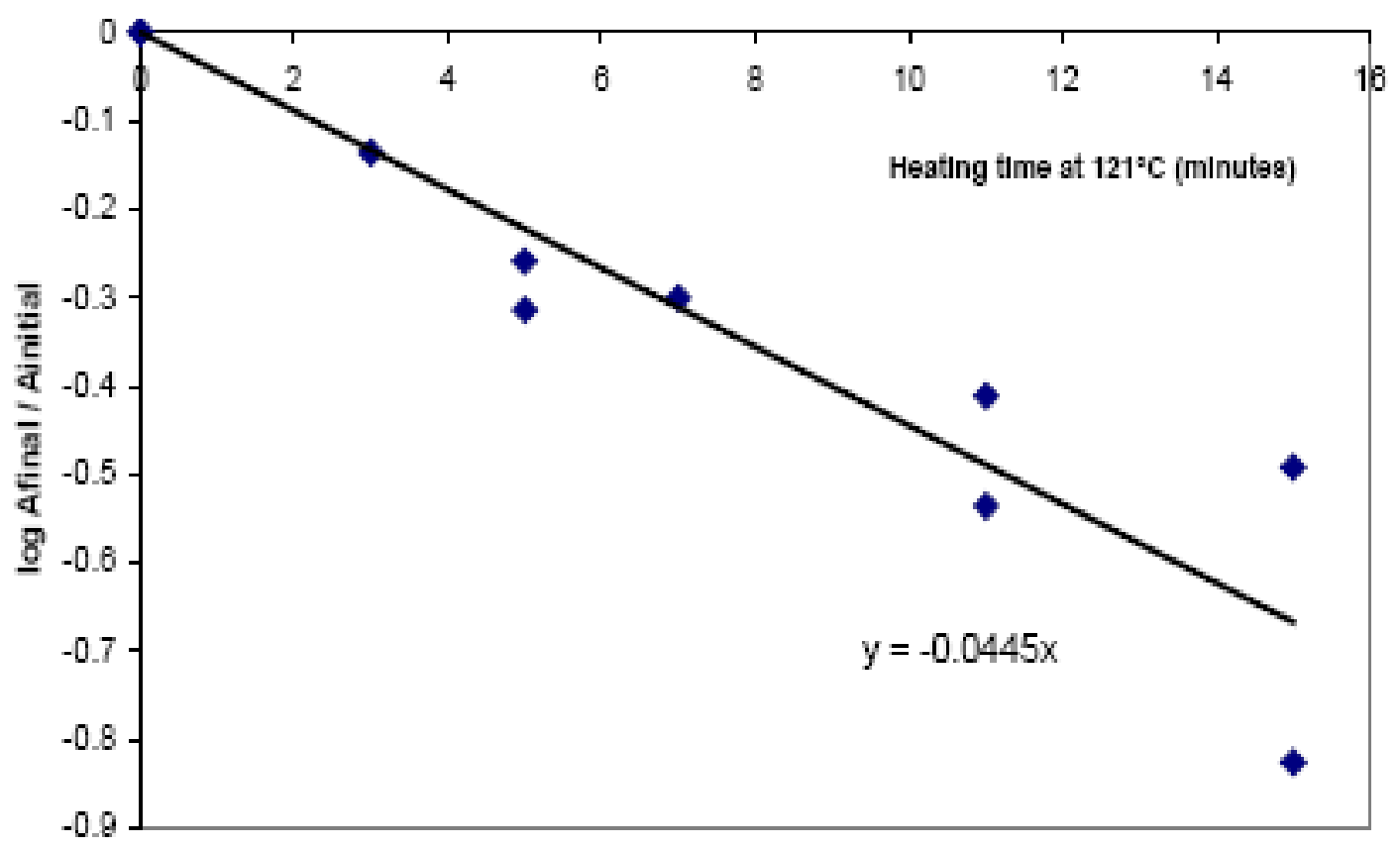

Figure 1. The ratio of activity for isothermal heating at $121 \mathrm{oC} . \mathrm{D}=22.5 \mathrm{mins}$. 
(a)

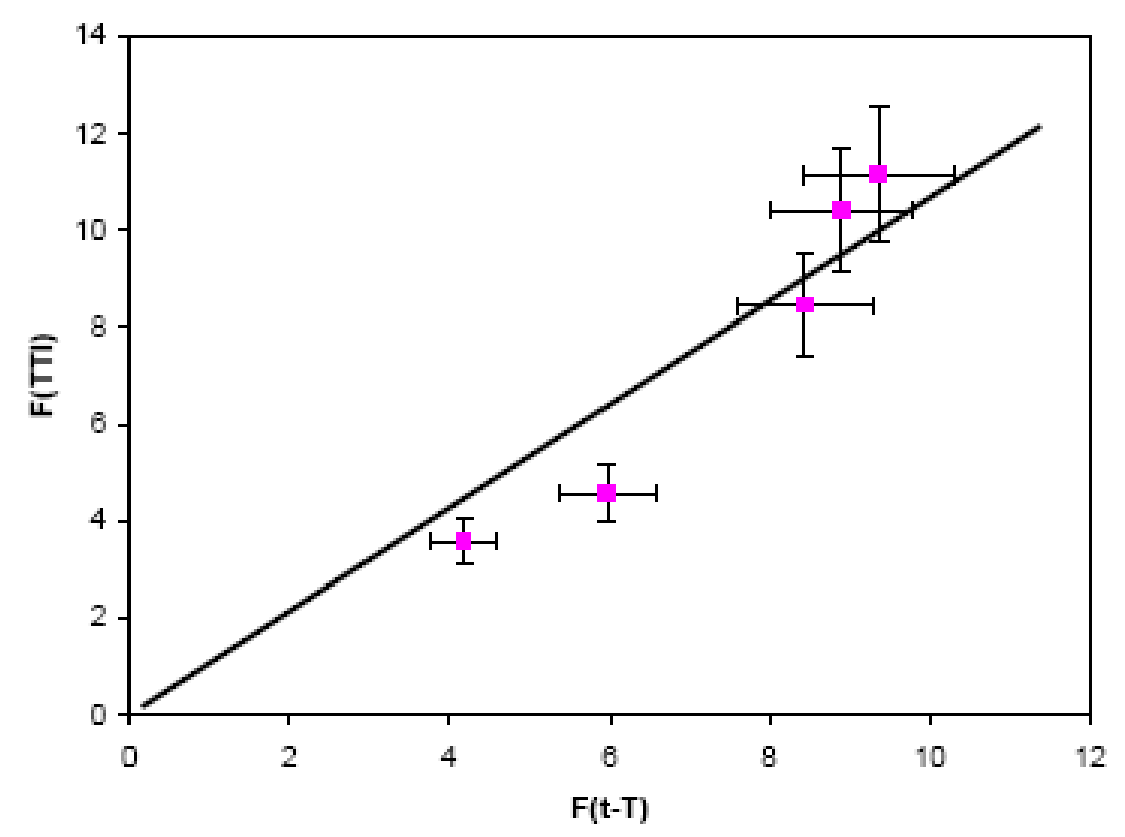

(b)

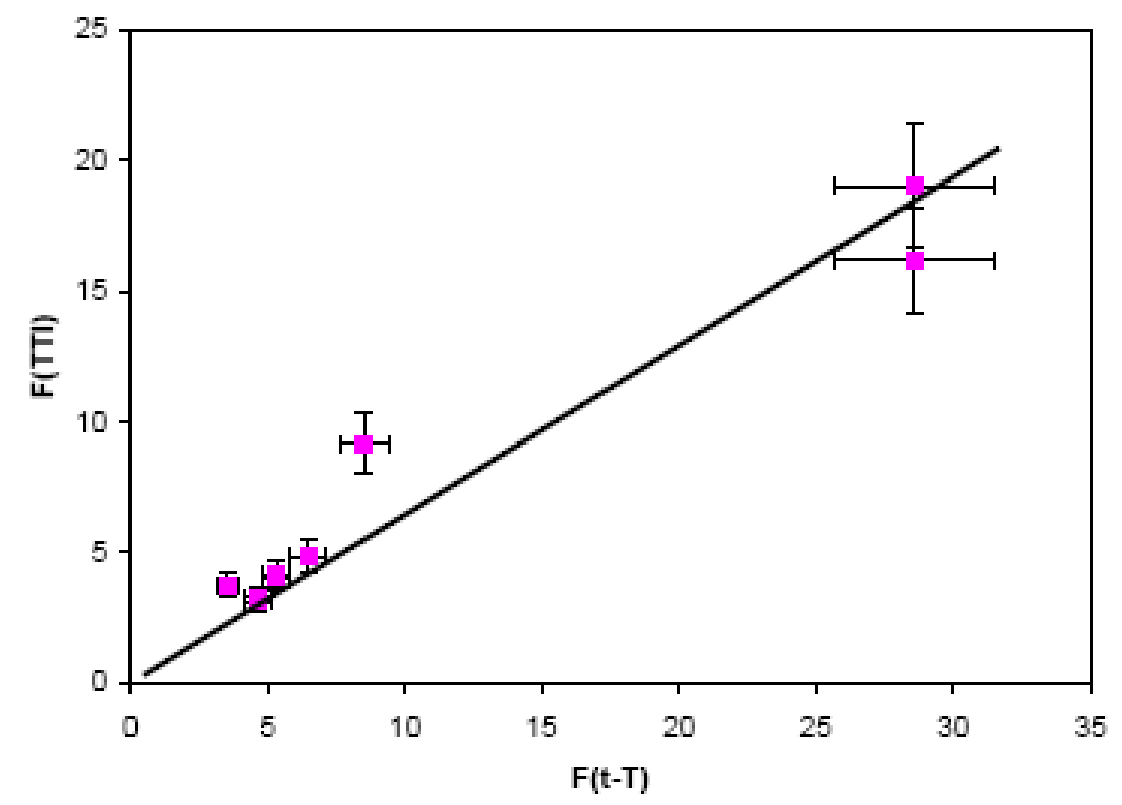

Figure 2. $\mathrm{F}(\mathrm{t}-\mathrm{T})$ and $\mathrm{F}(\mathrm{TTI})$ graphs for trials calculated using $\mathrm{D}_{121.1}$ of 21.4 mins. and a $\mathrm{z}$ of $10^{\circ} \mathrm{C}$. Fig. 2 a pouches in a Lagarde steam/air retort, Fig. 2b. cans in a FMC reel and spiral cooker/cooler. 